\title{
Restitución de tierras y derecho al medioambiente en Colombia: tensiones y proximidades en torno a la situación de los campesinos en zonas de reserva forestal ${ }^{*}$
}

Colombia's Land Restitution Program and Environmental Law: Tensions and Proximity on the Situation of the Farmers in Reservation Forest Zones

Restituição de terras e direito ao meio ambiente na Colômbia: tensões e proximidades em torno à situação dos camponeses em zonas de reserva florestal

\section{Efraín Cruz Gutiérrez **}

Andrés Mauricio Guzmán Rincón ${ }^{* * *}$

Recibido: 20 de octubre de 2015

Aprobado: 13 de mayo de 2016

Doi: dx.doi.org/10.12804/territ35.2016.07

\section{Para citar este artículo:}

Cruz, G. \& Guzmán, A. (2016). Restitución de tierras y derecho al medioambiente en Colombia: tensiones y proximidades en torno a la situación de los campesinos en zonas de reserva forestal. Territorios, 35, 149-170. Doi: dx.doi.org/10.12804/territ35.2016.07

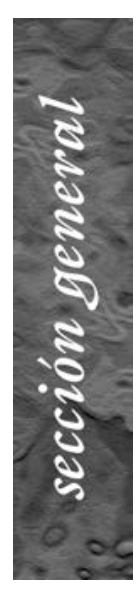

* Articulo producto de investigación en el marco del proyecto "constitucionalismo global, justicia transicionaly multiculturalismo: reflexiones a partir de las dinámicas de la restitución de tierras en Colombia y la reparación integral a comunidades indigenas" que se desarrolla desde el mes de febrero de 2015 en la Facultad de Derecho de la Universidad Libre de Colombia.

** Abogado de la Universidad Nacional de Colombia, Magister en derecho con énfasis en derecho de los recursos naturales de la Universidad Externado de Colombia. Asesor independiente. Correo electrónico efraincruzgutierrez@ gmail.com

** Abogado y magister en derecho de la Universidad 
Palabras clave

Restitución de tierras, zonas de reserva forestal, derecho al medio ambiente, Ley 2 de 1959,

Ley 1448 de 2011.

Keywords

Land restitution program, Transitional Justice, environmental law, Corrective Justice, PostConflict.

Palavras-chave

Restituição de terras, zonas de reserva florestal, direito ao meio ambiente, Lei 2 de 1959, Lei 1448 de 2011.

territarias 35
Resumen

La restitución de tierras como instrumento de reparación en el contexto de la justicia transicional en Colombia, incorpora importantes herramientas que denotan su potencialidad en la consecución de objetivos de justicia que van más allá de la justicia correctiva. En el presente artículo se reflexiona sobre la necesidad de comprenderla de forma coherente con las exigencias del derecho ambiental para lograr soluciones efectivas frente a las tensiones que se suscitan ante la exigencia de restitución en territorios que hacen parte de zonas de reserva forestal de Ley 2 de 1959, y en consecuencia mantienen ciertas restricciones para su adjudicación, uso y explotación. El examen precedente demuestra entonces que es posible identificar una dimensión ambiental de la restitución de tierras en el país.

\section{Abstract}

As any Transitional Justice mechanism, the land restitution program implemented in Colombia faces important challenges that involve principles of Constitutional Law and the International Law of Human Rights. This article reflects on the challenges that the implementation of the land restitution program will bring about, in particular, the proximity to environmental law. Our analytical framework to address this question revolves around the notion of Corrective Justice and its relationship with social and redistributive justice. Overall, the article maintains that the Colombia's land restitution has an environmental perspective.

\section{Resumo}

A restituição de terras como instrumento de reparação no contexto da justiça transicional na $\mathrm{Co}^{-}$ lômbia, incorpora importantes ferramentas que denotam a sua potencialidade na consecução de objetivos de justiça que vão para além da justiça corretiva. No presente artigo se reflexiona sobre a necessidade de compreende-la de forma coerente com as exigências do direito ambiental para conseguir soluções efetivas frente às tensões que se suscitam ante a exigência de restituição em territórios que fazem parte de zonas de reserva florestal de Lei $2^{\text {a }}$ de 1959 , e em consequência mantêm certas restrições para a sua adjudicação, uso e exploração. $\mathrm{O}$ exame precedente demonstra então que é possível identificar uma dimensão ambiental da restituição de terras no país. 


\section{Introducción}

El Estado colombiano ha adoptado una estrategia para la gestión de los recursos naturales a través de la política ambiental colombiana y la regulación de las zonas de reserva forestal, esta se encuentra contenida entre otras normas, en la Ley 2 de 1959 "por la cual se dictan normas sobre economía forestal de la Nación y conservación de recursos naturales renovables", el Decreto 2811 de 1974 "por el cual se dicta el Código Nacional de Recursos Naturales Renovables y de Protección al Medio Ambiente" y algunos apartados de la Ley 160 de 1994 "por la cual se crea el Sistema Nacional de Reforma Agraria y Desarrollo Rural Campesino, se establece un subsidio para la adquisición de tierras, se reforma el Instituto Colombiano de la Reforma Agraria y se dictan otras disposiciones".

Específicamente a través de la Ley 2 de 1959 se establecen reglas para la explotación de los recursos forestales y de conservación de las aguas, los suelos y la diversidad por medio de restricciones al uso de los predios que se encuentren en su interior, de igual manera se contempla que la adjudicación de baldíos de la $\mathrm{Na}-$ ción deberá efectuarse de conformidad con la reglamentación posterior que dicte el gobierno nacional. Sin embargo, más adelante, el Gobierno Nacional en uso de dicha facultad, a través del Decreto 2811 de 1974, contrariando en buena medida la filosofía de la Ley 2 de1959, proscribió la adjudicación de bienes públicos que se encontraran al interior de las áreas reservadas, postura que se reforzó posteriormente a través de la Ley 160 de 1994, al establecer en su artículo 65 que solo podrían ser objeto de adjudicación aquellos predios con vocación agropecuaria ${ }^{1}$.

Por otra parte, la Ley 1448 de 2011 a través de la cual se establecen mecanismos de reparación integral a las víctimas del conflicto armado, en lo que respecta a la restitución de tierras, establece que serán titulares de la misma, aquellas victimas que con ocasión del conflicto armado hayan sufrido el despojo o abandono de sus predios, siempre y cuando hayan perdido su relación de dominio, posesión o en el caso de los bienes públicos, la ocupación de predios que pretenda adquirir mediante adjudicación, esto significa, la explotación económica de tipo agropecuario sobre un terreno de dominio público que tiene dicha vocación y que es susceptible de ser apropiado por particulares. Es decir, específicamente frente a la adjudicación de baldíos, la Ley 1448 de 2011 efectúa una remisión normativa al régimen agrario y ambiental para determinar si en determinado contexto se cumplen los requisitos para acceder a la titulación respectiva.

Haciendo abstracción de la realidad en la que se aplican estos marcos normativos, podría sostenerse desprevenidamente que una persona víctima que con ocasión del conflicto armado haya perdido su relación de ocupación con un baldío ubicado al interior de una zona de reserva forestal, de conformidad con lo dispuesto en la Ley 2 de 1959, de acudir a la acción de restitución de tierras por conducto de la Ley 1448 de
Nacional de Colombia. Magister en derechos humanos y democratización de la Universidad Nacional de San Martín. Docente investigador de la Facultad de derecho de la Universidad Libre de Colombia. Correo electrónico andresm.guzmanr@unilibrebog.edu.co

${ }^{1}$ Igualmente, el artículo $9^{\circ}$ del Decreto 2664 de 1994, por el cual se reglamenta la adjudicación de tierras baldías, probibió la adjudicación de tierras que hagan parte de reservas territoriales del Estado.

territarias 35

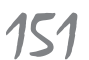


2011, no tendría derecho a la misma, atendiendo a que dicho predio de conformidad con el mencionado Decreto 2811 de 1974 no tendría la condición de adjudicable.

Frente a esta tensión, se han adoptado algunas soluciones parciales para hacer efectiva la restitución de tierras sin menoscabar el medioambiente, estas son: el proceso de sustracción de predios ubicados en zonas protegidas que son objeto de restitución de conformidad con lo dispuesto en la Resolución 629 de 2012 del Ministerio de Ambiente y desarrollo Rural y por otra parte sentencias de restitución en las que los jueces y magistrados especializados han ordenado la compensación en favor de los solicitantes o la restitución aunque limitando el uso de los predios para que cumplan con finalidades ambientales.

En todo caso dichas soluciones, por las razones que se abordarán en este artículo no logran constituirse en una salida adecuada al contexto del país, ni resuelven de forma efectiva ni unívoca la tensión identificada. Así las cosas, la disertación gira en torno a la siguiente pregunta ¿En este panorama qué salidas jurídicas resultan adecuadas a la situación colombiana para reconocer la importancia de ambos derechos en tensión $\mathrm{y}$ evitar soluciones que restrinjan de forma injustificada el ejercicio de los mismos?

Así las cosas, el objeto del presente artículo es reconstruir la existencia de esta tensión y explorar las salidas existentes para formular algunos parámetros que contribuyan a su solución desde una perspectiva que le de prevalencia al discurso constitucional y de derechos humanos, el resultado permitirá poner de manifiesto la necesaria articulación entre los objetivos de política social ambiental y la restitución de tierras.

La metodología dispuesta para tal fin se basó en el análisis de los marcos regulatorios de la situación descrita y de las soluciones dadas a la problemática, principalmente a través de la jurisprudencia especializada, y algunas normas reglamentarias posteriores proferidas por el gobierno nacional, dicho análisis se contextualiza y reelabora a través de los estudios técnicos disponibles y la información especializada sobre el tema. Por último se evalúan estas respuestas teniendo como referente teórico-normativo la necesidad de armonizar la existencia de tensiones entre principios constitucionales de igual jerarquía a través de estructuras de ponderación.

En la primera parte abordará el estudio de la política ambiental en Colombia teniendo como referente principal el marco regulatorio de las zonas de reserva forestal. En la segunda, se describe sucintamente el ámbito de aplicación de la ley 1448 de 2011 frente a los ocupantes de baldíos al interior de zonas protegidas y en la tercera parte luego de analizar brevemente las soluciones parciales a la problemática identificada, se esgrimen algunas lineamientos en torno a los cuales se podrá reflexionar sobre la proximidad entre la restitución de tierras y la protección al medioambiente. 


\section{Facultad del Estado de reservar zonas para la protección ambiental a partir de la Ley 2 de 1959}

Teniendo en cuenta la obligación del Estado y su capacidad institucional para garantizar del derecho a gozar de un ambiente sano, este cuenta con la facultad de implementar en el territorio distintas figuras que le permitan gestionar los recursos naturales renovables de conformidad con los preceptos de la protección ambiental y del desarrollo.

El contexto en el cual se promulga la Ley 2 de 1959, y a partir de la cual hoy en día se sustenta en buena medida la facultad estatal para reservar zonas encaminadas a la protección ambiental, se profirió en un contexto en el que el país por un lado, se enfrascaba en profundas discusiones frente a la distribución de la tierra entre los habitantes, acaparada entre los latifundistas y los colonos, y de otro lado presenciaba la violencia bipartidista. Vale la pena mencionar que en buena medida la informalidad en los derechos de propiedad ha dado lugar a un sinnúmero de conflictos por la tierra que han alimentado desde sus orígenes el conflicto armado (Sánchez Torres, Fazio Vargas, \& Lopez Uribe, 2007).

Mientras en materia agraria se formulaban marcos jurídicos para buscar soluciones para la redistribución de la tierra, en cuestiones ambientales ya existía una intención de regular la forma en que los bosques deberían ser aprovechados, por ejemplo a través de la Ley 119 de 1919 que reformó el Código Fiscal vigente para la época, se faculta al Gobierno Nacional para reservar territorios a efectos de implementar la explotación de los recursos naturales, mientras que el Decreto 2278 de 1953, determinó que podrían constituirse zonas protectoras y de interés general con fines de regular la conservación del bosque o crearlo nuevamente si es que este ha desaparecido con el fin de proteger los suelos y las aguas.

Dentro de la categoría de áreas de protección ambiental que el Estado tiene la facultad de reservar, la Ley 2 de 1959 corresponde a uno de los regímenes jurídicos aplicables a las afectaciones ambientales sobre los recursos forestales. El objeto de la Ley está claramente identificado en su artículo $1^{\circ}$ al exponer que dicho cuerpo normativo versará sobre aspectos que permitan el "desarrollo de la economía forestal y protección de los suelos, las aguas y la vida silvestre", indicando que contiene objetivos mixtos de conservación de los recursos naturales y de fijar reglas para su adecuada explotación.

De conformidad con lo anterior, la Ley estableció bajo el carácter de Zonas Forestales Protectoras y Bosques de Interés General siete Zonas de Reserva Forestal ${ }^{2}$. En esa línea, el Decreto - Ley 2811 de 1974 cuenta con un capítulo dedicado a las Áreas de Reserva Forestal en el cual establece que "se denomina área de reserva forestal la zona de propiedad pública o privada reservada" que tenga como fines el establecimiento o mantenimiento y utilización racionales de las áreas forestales. Así mismo, el artículo 207 sostiene que 2i) Zona de Reserva Forestal del Pacífico; ii) Zona de Reserva Forestal Central; iii) Zona de Reserva Forestal del Rio Magdalena; iv) Zona de Reserva Forestal de la Sierra Nevada de Santa Marta; v) Zona de Reserva Forestal de la Serranía de los Motilones; vi) Zona de Reserva Forestal del Cocuy, y, vii) Zona de Reserva Forestal de la Amazonía. 
${ }^{3}$ El artículo $9^{\circ}$ de la Ley 2 de 1959 establece que a efectos de la conservación de los suelosy de las aguasel uso de "los terrenos de propiedad privada que se encuentren localizados dentro de los límites de las Zonas de Reserva Forestal o de Bosques Nacionales" será objeto de reglamentación, lo cualfue realizado por medio del Decreto 2811 de 1974.

\section{territarias 35}

las reservas forestales únicamente pueden destinarse "al aprovechamiento racional permanente de los bosques que en ella existan o se establezcan y, en todo caso, deberá garantizarse la recuperación y supervivencia de los bosques", pero que en caso en que ello no se pueda asegurar, los titulares de la concesión o permiso de explotación deberán pagar la tasa adicional que aplica para los aprovechamientos forestales únicos.

En virtud de ello resulta claro que la finalidad de las afectaciones de la Ley 2 de 1959, persigue la protección de los recursos naturales ante su explotación indiscriminada, y que la protección del ambiente y de los recursos naturales como desarrollo de principios constitucionales, son una manifestación propia del bienestar y el interés público que tienen relación el principio de la función social de la propiedad.

\subsection{Relaciones jurídicas con la tierra, reconocidas al interior de las Zonas de Reserva Forestal}

Las relaciones jurídicas que se pueden establecer con los predios al interior de las Zonas de Reserva Forestal debe analizarse a la luz de la naturaleza de los inmuebles que la conforman, pues, como se ha visto, al interior de estas pueden coexistir predios de propiedad privada o baldíos de la Nación.

En ese sentido, sobre los predios de dominio privado será posible ejercer derechos de propiedad con las limitaciones al uso que implica la categoría ambiental ${ }^{3}$ así como derechos de posesión por parte de aquellos que no son propietarios jurídicamente reconocidos.

En el caso de los baldíos de la Nación la situación merece un análisis más detallado con el fin de dilucidar qué se requiere para que un inmueble sea considerado como tal. De acuerdo con el artículo 102 de la Constitución Nacional "el territorio, con los bienes públicos que de él forman parte, pertenecen a la Nación" y en concordancia con ello, el artículo 674 del Código Civil establece que en efecto existen bienes cuyo dominio corresponde a la República, distinguiendo aquellos cuyo uso pertenece generalmente a todos los habitantes del territorio, que son llamados bienes de uso público, y aquellos cuyo uso no pertenece a los habitantes, que son considerados bienes fiscales.

El artículo 675 del Código Civil, por su parte, describe los baldíos como bienes públicos, o de la Unión, que están conformados por "todas las tierras que estando situadas dentro de los límites territoriales carecen de otro dueño". Dicha descripción podría dar a entender que los baldíos pueden ser indistintamente bienes de uso público o bienes fiscales. No obstante, el numeral 18 del artículo 150 de la Constitución Nacional otorga la facultad al Congreso de la República para "dictar las normas sobre apropiación o adjudicación y recuperación de tierras baldías" lo que evidencia su característica esencial de ser bienes públicos con vocación de adjudicación a particulares.

Teniendo en cuenta lo anterior, los bienes baldíos son bienes públicos cuyo uso 
no pertenece generalmente a todos los habitantes pero que son susceptibles de cambiar su régimen jurídico a aquel de dominio privado a favor de particulares en virtud de la Ley, es decir, son bienes fiscales adjudicables. Aquellos bienes públicos cuyo uso no pertenece a todos los habitantes y que no son susceptibles de ser adjudicados son llamados bienes fiscales propiamente dichos.

$\mathrm{Al}$ respecto, la Ley 160 de 1994 "por la cual se crea el Sistema Nacional de Reforma Agraria y Desarrollo Rural Campesino, se establece un subsidio para la adquisición de tierras, se reforma el Instituto Colombiano de la Reforma Agraria y se dictan otras disposiciones". contempla, entre otras, las reglas a partir de las cuales es posible efectuar la adjudicación de baldíos. Así por ejemplo el artículo 65 de la Ley 160 de 1994 contempla que la ocupación no es un modo de adquirir la propiedad de tierras baldías debido a que esta solo es posible adquirirla mediante un título traslaticio de dominio otorgado por el Estado a los particulares, guardando plena coherencia con la teoría sobre título y modo. De otro lado, también hace distinción entre los ocupantes de baldíos y los poseedores, en el sentido en que la sola ocupación genera solo una mera expectativa de adjudicación frente al Estado, razón por la cual a pesar de ser adjudicables, los bienes baldíos continúan siendo imprescriptibles.

En ese orden de ideas, una primera lectura de la Ley 2 de 1959 permitiría la ocupación de tierras baldías de la Nación, pues dejó abierta la posibilidad de efectuar reglamentaciones posteriores por parte del gobierno nacional ${ }^{4}$. No obstante, como se verá, el panorama institucional actual ofrece un escenario completamente distinto.

\subsubsection{Actividades económicas permitidas al interior de las Zonas de Reserva Forestal de Ley 2 de 1959}

A pesar de que el régimen de la Ley 2 de 1959 contiene un componente de conservación a los recursos naturales que hagan parte de las áreas reservadas, no hay que perder de vista que las finalidades de la Ley, $\mathrm{y}$ atendiendo a las disposiciones constitucionales actuales, se encuentran ajustadas a la idea rectora de desarrollo sostenible, bajo la cual se propende por la armonización entre los objetivos de la conservación ambiental y la gestión de los recursos naturales en materia de explotación.

De conformidad con ello, la Ley ha determinado el tipo de actividades cuyo desarrollo es permitido sobre los inmuebles que hacen parte de estas tierras. Así las cosas, dispuso que las Reservas deberían someterse a procesos de gestión ambiental planeados técnicamente a efectos de determinar cuáles de sus componentes podrían usarse para distintas actividades de acuerdo a la vocación de los suelos y sus características biológicas.

En relación con los recursos forestales por ejemplo, el artículo $4^{\circ}$ de la Ley 2 de 1959 determinó que los bosques comprendidos entre las Zonas de Reserva Forestal deberían someterse a un Plan de Ordenación Forestal que corresponda a su manejo
${ }^{4}$ Ley 2 de 1959. Articulo 7. "La ocupación de tierras baldias estará sujeta a las reglamentaciones que dicte el Gobierno con el objeto de evitar la erosión de las tierras y proveer a la conservación de las aguas (...)”. 
${ }^{5}$ Tales como i) aquellas inberentes para realizar la administración de las mismas por parte de la autoridad ambiental; ii) montaje de infraestructura para desarrollar actividades cientificas sobre diversidad biológica; iii) actividades tendientes hacia la restauración ecológica y recuperación o rehabilitación de ecosistemas, entre otras.

${ }^{6}$ Ley 2 de 1959. Artículo 7. "La ocupación de tierras baldias estará sujeta a las reglamentaciones que dicte el Gobierno con el objeto de evitar la erosión de las tierras y proveer a la conservación de las aguas. $A l$ dictar tal reglamentación, el Gobierno podrá disponer que no serán ocupables ni susceptibles de adjudicación aquellas porciones de terreno donde la conservación de los bosques sea necesaria para los fines arriba indicados, pero podrá también contemplar la posibilidad de comprender en las adjudicaciones, bosques que deban mantenerse para los mismos fines, quedando sujeta en este caso la respectiva adjudicación a la cláusula de reversión si las zonas de bosques adjudicadasfueren objeto de desmonte o no se explotaren conforme a las reglamentaciones que dicte el Gobierno”. (subrayas y negrilla fuera de texto).

\section{territarios 35}

y protección y cuya implementación estaría a cargo del Ministerio de Agricultura.

De igual manera, en el artículo 204 de la Ley 1450 de 2011, se dispuso que el Ministerio de Ambiente y Desarrollo Sostenible será quien deba determinar las actividades que generan un bajo impacto ambiental y beneficio social para que se puedan desarrollar allí sin la necesidad de llevar a cabo la sustracción. Conforme a ello se expidió la Resolución 1527 de 2012, la cual estableció cuales eran estas actividades ${ }^{5}$, en ese sentido, las actividades no previstas explícitamente requerirán para su ejercicio, el adelantamiento de la sustracción respectiva con el fin de levantar la afectación sobre el predio al encontrarse en zona protegida. Precisamente, este es el caso de las actividades agropecuarias que se ejercen de forma cotidiana por los campesinos como forma de vida. En tal sentido, la Ley 2 de 1959 en su artículo $3^{\circ}$ dispuso que mientras el Estado adelantaba las labores de estudio y clasificación de los suelos del país, el Instituto Geográfico Agustín Codazzi determinaría qué lugares serían aptos para el desarrollo de actividades agropecuarias con el fin de sustraerlas y llevar a cabo dichas actividades.

Pero así mismo, la Ley 2 de 1959 dejó abierta la posibilidad para que las ocupaciones pudieran realizarse sobre baldíos de la Nación con el fin de adquirir mediante adjudicación la propiedad de los predios. En consecuencia el gobierno tendría la posibilidad de optar por dos alternativas, por un lado proscribir las adjudicaciones de baldíos, y de otro, permitirlas siempre y cuando los usos al recurso forestal no soslayaran las finalidades protectoras de las reservas $^{6}$. Sin embargo, en oposición al sentido de Ley 2 de 1959, bajo el cual se permiten actividades económicas en su interior al mismo tiempo que se establecen reglas para la protección de los recursos naturales, el artículo 209 del Decreto - Ley 2811 de 1974 optó por prohibir expresamente la adjudicación de tierras baldías que estuvieran al interior de las Zonas de Reserva Forestal. En la misma dirección el artículo 65 de la Ley 160 de 1994, estableció que para la adjudicación de tierras baldías se deberá demostrar, entre otras cosas, que el predio solicitado tenga vocación agropecuaria.

En consecuencia, el desarrollo normativo posterior a la Ley 2 de 1959, al establecer las actividades agropecuarias como única forma de explotación de tierras a efectos de su adjudicación, cerró la puerta para que las áreas reservadas aportaran plenamente a los procesos de desarrollo, y además, cambió el alcance de la afectación ambiental sobre los bienes de dominio público pues los despojó de su naturaleza adjudicable. Del mismo modo, este conjunto de normas llevaron a contemplar al campesino sujeto de reforma agraria como aquel que únicamente puede desarrollar actividades agropecuarias, negándole de esta forma el acceso formal a la tierra y la posibilidad de participar en estrategias de protección a los recursos naturales.

Toda esta situación resulta problemática, pues como se verá, existe una alta tasa de informalidad en la tenencia de la tierra y hasta hace muy poco existe un proceso de 
ordenación y zonificación de las reservas forestales que identifica, entre otras, los límites de las reservas. Por esta razón, cabe la posibilidad de que muchas personas que explotan predios en su interior lo estén haciendo sobre bienes públicos, desconozcan que estos se encuentran afectados por el régimen de la Ley 2 de 1959, y que en consecuencia, se les hayan generado expectativas falsas en cuanto a su propiedad y carezcan de cualquier posibilidad de ser adjudicatarios o de reclamar sus derechos patrimoniales en relación con sus inmuebles.

\subsection{El proceso de sustracción de predios de las Zonas de Reserva Forestal de la Ley 2 de 1959}

Así como la administración tiene la facultad para reservar áreas con el fin de establecer formas para su uso y administración, también tiene la facultad de levantar dicha afectación cuando se considera necesario para cumplir con otros fines y objetivos a partir de la gestión del recurso.

En ese sentido, el artículo 210 del Decreto - Ley 2811 de 1974 señala las condiciones que se deben cumplir para que este proceso sea procedente. Por un lado indica que deben existir razones de utilidad pública o interés general que conlleven a que sea necesario afectar considerablemente los recursos forestales o el uso de los suelos como consecuencia del desarrollo de actividades económicas o cuando se demuestre que los suelos pueden ser utilizados en una actividad distinta a la forestal que no afecten los fines de protección ambiental de la reserva.
$\mathrm{Al}$ respecto, el numeral 18 del artículo $5^{\circ}$ de la Ley 99 de 1993 le da la competencia al Ministerio de Ambiente y Desarrollo Sostenible para "sustraer las áreas que integran el Sistema de Parques Nacionales Naturales y las reservas forestales nacionales", sin embargo, la expresión sustraer fue declarada condicionalmente exequible por la Corte Constitucional mediante Sentencia C-649 de 1997 M.P. Antonio Barrera Carbonell, en el sentido en que esta solo aplica para las reservas forestales nacionales y no para las áreas que integran el Sistema de Parques Nacionales Naturales ${ }^{7}$.

De otro lado, el artículo $2^{\circ}$ del Decreto 3570 de 2011 recalca la competencia del Ministerio de Ambiente y Desarrollo Sostenible para sustraer áreas forestales nacionales, y recientemente, el parágrafo $3^{\circ}$ del artículo 204 de la Ley 1450 de 2011 indica que el proceso de sustracción de las Zonas de Reserva Forestal de la Ley 2 de 1959 se debe soportar en estudios técnicos por parte de la autoridad ambiental y en actuaciones coordinadas entre los ministerios involucrados en los procesos y actividades que se pretenden desarrollar.

A pesar de este nuevo marco normativo, que privilegia las finalidades de protección y conservación del recurso forestal, podría decirse que las afectaciones establecidas en la Ley 2 de 1959 han venido perdiendo peso formal y material como estrategia de conservación dentro del ordenamiento jurídico. Por ejemplo, informes institucionales sostuvieron en su momento que una vez proferida la Ley 2 de 1959 la extensión total de las siete Reservas Fores-
Igualmente, por medio del artículo 31 de la Ley 99 de 1993, esta competencia también le habia sido otorgada a las Corporaciones Autónomas Regionales a nivel local, pero dicha facultad fue declarada inexequible por la Corte Constitucional mediante Sentencia C-598 de 2010, M.P. Mauricio González Cuervo, bajo el entendido en que la inconstitucionalidad declarada "se basa en la oposición que se presenta entre la facultad de sustraer áreas de valores excepcionales en materia ambiental y la realización de los fines sociales y ecológicos propios del Estado Social de Derecho". Es decir, no basta que exista la facultad de declarar la existencia de parques naturales de carácter regional para poder desafectarlos, pues resulta de mayor importancia la protección de los recursos que alli se pueden albergar y el nivel de protección que les otorga la constitución nacional en virtud del articulo 63 de la Constitución Politica. Si bien la inexequibildad se da a la luz de la importancia de los parques naturales nacionales y regionales, esta no fue condicionada por lo que se entiende que tampoco es procedente que se sustraigan reservas forestales por parte de las Corporaciones Autónomas Regionales.

territarios 35 
tales cubría el $57.17 \%$ del territorio nacional, no obstante, y en virtud de los procesos de colonización, a 2009 se habían sustraído alrededor del $12 \%$ de las mismas a lo largo de todo el territorio nacional, razón por la cual el total de las mismas se redujo a un $45 \%$ de la superficie terrestre de Colombia (Proyecto protección de tierras, 2009, pp. 12-13).

Teniendo en cuenta que las sustracciones se realizan cuando las actividades a ser desarrolladas a su interior no corresponden con las finalidades de conservación y de uso racional de los recursos naturales que allí existen, es posible sostener que el enfoque que tiene Colombia respecto al desarrollo, resulta materialmente opuesto a las consideraciones normativas que convocan a la gestión de los recursos naturales en plena sintonía con las finalidades del desarrollo sostenible.

En todo caso, vale la pena mencionar que además de lo indicado, en Colombia existen comunidades que se han asentado históricamente en tierras baldías de la $\mathrm{Na}$ ción, algunas al interior de Zonas de Reserva Forestal de Ley 2 de 1959, quienes a raíz de las explotaciones de los predios lograron consolidar sus proyectos de vida y construir tejido social. Estas situaciones merecen ser atendidas y respetadas en ocasiones mediante la sustracción de las reservas, en tanto el nivel de intervención sobre estas resulta tan elevado que las características que en principio merecieron ser protegidas por la afectación ambiental, en la actualidad son completamente distintas y de ninguna manera responden a los objetivos de la Ley
2 de 1959. Así por ejemplo, la Resolución 763 de 2004 del Ministerio de Ambiente, Vivienda y Desarrollo Territorial tiene como objeto sustraer los cascos urbanos y sus áreas de expansión que se encuentran al interior de áreas de reserva forestal de Ley 2, los cuales se estimaban a 2009 en un número igual a 357 , superponiéndose en un área de 51.024.034 hectáreas (Proyecto Tierras y Patrimonio, 2009, p. 45.)

Dentro de ese marco, y con fundamento en las facultades que le otorgaran la Ley 99 de 1993, el Decreto 3570 de 2011 y la Ley 1450 de 2011 en materia de gestión de los recursos forestales en el país, el Ministerio de Ambiente y Desarrollo Sostenible afirma que luego de varios años ha culminado finalmente el proceso de ordenación y zonificación de las siete Reservas Forestales de la Ley 2 de 1959, y que producto de ello, las anteriores áreas reservadas se encuentran ordenadas y zonificadas.

\section{Restitución de tierras al interior de las zonas protegidas}

Las estrategias de gestión de los recursos naturales no solo afectan a los ciudadanos colombianos de forma individual, sino que tienen repercusiones sobre grupos poblacionales que pueden ser identificados claramente. Para el caso de la presente disertación, ya hemos determinado como se concibe una de las estrategias de protección a los recursos naturales, a través de las $\mathrm{Zo}_{\mathrm{O}^{-}}$ nas de Reserva Forestal de Ley 2 de 1959. En este apartado identificaremos a un grupo poblacional específico, las víctimas del

\section{territarias 35}


conflicto armado, que tienen interés sobre las tierras, y determinaremos el régimen jurídico con que se cuenta para garantizarles el acceso a dicho recurso aunque específicamente en relación con predios que se encuentren en estas zonas.

En el marco del cumplimiento a la necesidad de replantear la política de atención a la población desplazada, el gobierno nacional reformuló el sistema para atender a las personas víctimas de desplazamiento forzado por la violencia, que también perdieron sus tierras, lo anterior principalmente a partir de la expedición de la Ley 1448 de 2011 . En dicho instrumento se destaca el principio de progresividad, conforme al cual 'Tas medidas de restitución contempladas en la presente ley tienen como objetivo el de propender de manera progresiva por el restablecimiento del proyecto de vida de las víctimas". Igualmente se establece el principio de estabilización en virtud del cual se señala que "las víctimas del desplazamiento forzado y del abandono forzado, tienen derecho a un retorno o reubicación voluntaria en condiciones de sostenibilidad, seguridad y dignidad"; y el de seguridad jurídica en virtud del cual "se propenderá por la titulación de la propiedad como medida de restitución, considerando la relación jurídica que tenían las víctimas con los predios objeto de restitución o compensación”.

La Ley intenta superar el mero reconocimiento formal del derecho a la restitución como mecanismo para satisfacer una amplia gama de derechos prestacionales, y bajo el principio de progresividad en consonancia con los de estabilización y de seguridad jurí- dica, se obliga a que la restitución se traduzca en el acceso a los derechos de propiedad con el fin de solucionar los altos índices de informalidad en la tenencia de la tierra de la población campesina que ha sido victimizada con ocasión del conflicto armado.

Para ser titular de la acción de restitución de tierras las personas solicitantes deben cumplir los siguientes requisitos: i) que hayan tenido que soportar un perjuicio en virtud de infracciones al DIH o graves violaciones a las normas de tipo internacional de derechos humanos en el marco del conflicto armado; ii) que los hechos generadores del perjuicio anteriormente señalado se hayan ocurrido posterior al 1 de enero de 1991 y previo al término de vigencia de la Ley, esto es, hasta el 10 de junio de 2021 ; iii) que el hecho victimizante haya ocasionado de forma directa o indirecta el despojo o el abandono forzado de tierras, y iv) que las personas que hayan sufrido el hecho victimizante tuvieran la calidad jurídica de propietarios, poseedores o explotadores de baldíos cuya propiedad se pretenda adquirir mediante adjudicación.

Por obvias razones, vale la pena detenerse sobre este último requisito. Como ya se explicó anteriormente, los propietarios y los poseedores se reputarán de inmuebles propios del régimen de derecho privado, mientras que los explotadores de baldios no serán otros que los ocupantes reconocidos por la Ley agraria.

Sobre este particular, el precitado artículo 65 de la Ley 160 de 1994, por medio del cual se dictan las reglas generales para la adquisición de tierras baldías de territarias 35

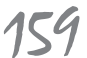


${ }^{8}$ Por ejemplo, el artículo 74 se refiere a "explotador económico de un baldio", el articulo 75 hace referencia a los "explotadores de baldios”, y los articulos 76 , 77, 78, 84 y 91 hablan sobre "ocupación" y "ocupante" respectivamente.

territarias 35 la Nación, califica a quienes se encuentren sobre este tipo de bienes bajo la categoría de ocupantes de tierras baldías, razón por la cual, debe interpretarse que esta deberá ser la calidad jurídica de los solicitantes de restitución de tierras públicas, aun cuando la Ley 1448 de 2011 contemple expresiones que pueden generar confusiones al referirse a esta de forma diversa ${ }^{8}$.

Conforme a todo lo anterior, se dilucida que la acción de restitución opera para todas aquellas personas que tengan algún tipo de relación con la tierra, ya sea a favor de sus propietarios, poseedores u ocupantes, no obstante, frente a estos últimos se excluyen aquellas ocupaciones de predios públicos pero que no tienen vocación agropecuaria, es decir, que son inadjudicables de acuerdo al régimen que se estudió en el acápite inmediatamente anterior de este artículo.

Igualmente, se exceptúan aquellas que tienen una mera tenencia sobre los mismos, es decir, aquellas personas que teniendo la materialidad del inmueble, reconocen mejor derecho sobre el mismo, como es el caso de los arrendatarios, aparceros o usufructuarios, entre otros, que son aquellas formas predominantes en que las personas se relacionan con la propiedad rural. En todo caso, en la Sentencia C-715 de 2012, la Corte Constitucional estableció que si bien es cierto que la tenencia es un título precario que no tiene el alcance jurídico para dar lugar a la restitución del bien inmueble, frente a esta población es posible establecer otras formas de reparación contenidas en la Ley 1448 de 2011 , como por ejemplo, la indemnización.
De cualquier forma, la restitución se manifiesta de formas distintas dependiendo de la calidad jurídica de las personas que la solicitan. Un asunto que resulta común para todas aquellas personas que pretenden acceder a la restitución tiene que ver con la garantía de que el Estado, por mandato del artículo 72 de la Ley 1448 de 2011 , deberá buscar que la restitución se logre jurídica y materialmente. A pesar de que el proceso de restitución de tierras es uno solo, la forma en que se logra la materialización de este objetivo variará de conformidad a las calidades jurídicas de los solicitantes en relación con sus predios reclamados.

En el caso de los ocupantes de baldíos de la Nación, sin perjuicio de la estabilidad y progresividad, el principio de seguridad jurídica cobra especial relevancia, pues como se ha ido sosteniendo, existen altos niveles de informalidad en la tenencia de la tierra, y además, es deber constitucional del Estado promover el acceso a la propiedad rural. En ese sentido, la Ley estableció un régimen especial para dar tratamiento a estos casos, en virtud del cual se dispuso que como resultado del proceso de restitución, el ocupante de un baldío que haya sido víctima del conflicto armado gozará de la adjudicación del derecho de propiedad si al momento de dictarse la sentencia se ha cumplido con las condiciones para ello.

En todo caso, la norma también previó que algunas de esas condiciones eran imposibles de ser cumplidas por la situación de desplazamiento, en especial aquellas que se derivan de la necesidad de ejercer un contacto directo con las tierras que se 
pretende adjudicar. Por esa razón, dispuso que al momento de dictar sentencia, el juez especializado en restitución de tierras no deberá tener en cuenta la duración de la explotación económica establecida en la Ley 160 de 1994, por el contrario en el artículo 74 de la Ley 1448 de 2011 se estableció que para la adjudicación del derecho de propiedad al restituido, no se tendrá en cuenta la duración de dicha explotación.

Bajo ese argumento, tampoco se deberá demostrar que la víctima de desplazamiento forzado, en efecto, está realizando una explotación económica sobre las dos terceras partes del predio conforme a los usos agropecuarios determinados por el INCODER (Hoy en liquidación). A efectos de la adjudicación, será únicamente necesario para el interesado demostrar que es víctima al tenor del artículo $3^{\circ}$ y que el predio tiene vocación de adjudicación, situación que evidentemente es un gran escollo para aquellos que dejaron abandonadas tierras de dominio público al interior de Zonas de Reserva Forestal de Ley 2 de 1959 , pues como se ha visto, estas no tienen calidad para ser adjudicadas en tanto la afectación ambiental es excluyente frente al desarrollo de actividades agropecuarias.

\section{Respuestas actuales frente a los imperativos de lograr la restitución de tierras pero garantizando la sostenibilidad medioambiental}

De acuerdo a lo abordado hasta ahora se observa que los ocupantes de baldíos en Zonas de Reserva Forestal de Ley 2 de
1959 no podrían acceder a la restitución de tierras en tanto los predios que perdieron con ocasión del conflicto armado se han tornado inadjudicables. Este fenómeno ocurre en un contexto en el que los campesinos han adquirido sus tierras y han permanecido en ellas predominantemente mediante la informalidad; las Zonas de Reserva Forestal de la Ley 2 de 1959, abarcan una magnitud amplia del territorio nacional; y el proceso de construcción territorial se ha dado de forma desordenada, ya que al menos el 10\% de las cabeceras municipales se encuentran dentro de las reservas. Así las cosas, el nivel de intervención sobre las áreas reservadas ha sido de tal importancia y notoriedad, que ha expedido normas encaminadas a sustraer porciones geográficas que correspondan a las cabeceras municipales, sacrificando las finalidades ambientales sobre la expansión y consolidación territorial.

Frente a este panorama surge el interrogante respecto de cómo asegurar la restitución de tierras a las víctimas del conflicto sin que esto implique un menoscabo o restricción injustificada del derecho al medioambiente.

El Estado colombiano ha venido dando solución a la tensión existente por medio de la eliminación de las afectaciones ambientales que pesan sobre los predios objeto de restitución a través de la Resolución 629 de 2012 del Ministerio de Medio Ambiente y desarrollo Rural, pues al no existir estas, automáticamente dichos predios adquieren la vocación de adjudicabilidad y por tanto, se cumplirían los requisitos 
${ }^{9}$ Fuente: Entrevista efectuada a la Dirección Juridica de Restitución - Unidad Administrativa Especial de Gestión de Restitución de Tierras Despojadas. Con corte a 15 de mayo de 2015.

territarias 35 de la Ley 1448 de 2011 para ser entregados a los campesinos por medio de la restitución de tierras. De cualquier modo, llama la atención el hecho de que la normatividad sobre predios sustraídos impone una serie de condicionamientos para su uso, pues de conformidad con ellos resulta claro que están encaminados al cumplimiento de finalidades de conservación y de aprovechamiento de los recursos naturales de forma similar a como lo establece la Ley 2 de 1959.

Si la sustracción de las reservas pretende sacar a los predios que allí se encuentran del sometimiento a un régimen ambiental, pero como resultado de la aplicación de la Resolución 629 de 2012 los predios en efecto dejan de estar reservados pero se les imprimen limitaciones al uso similares a las establecidas en la Ley 2 de 1959, vale la pena preguntarse por la pertinencia de los procesos de sustracción.

Teniendo en cuenta que estos se fundamentan en el proceso de ordenación de las reservas, en efecto representan un desgaste administrativo, pues habrá que realizar la ordenación y luego el proceso de sustracción para determinar que efectivamente los predios allí incluidos deben someterse a un régimen de uso acorde con los fines de la reserva sustraída.

\subsection{La solución desde la judicatura: la compensación}

De acuerdo con los artículos 72 y 73 de la Ley 1448 de 2011 , la restitución será la primera opción de reparación, es decir, se propenderá por devolver a las víctimas las mismas tierras que perdieron con ocasión del conflicto armado. Si ello no es posible, se optará por la compensación económica o en especie, siempre y cuando se cumplan las condiciones del artículo 97, es decir, i) que sean predios ubicados en zonas de alto riesgo o amenaza de catástrofes naturales; ii) que sean predio sobre los cuales se hayan presentado despojos sucesivos y ya se haya restituido a otra víctima; iii) cuando la restitución del predio implique un riesgo para la vida e integridad del solicitante o su familia; o iv) cuando el predio solicitado se encuentre total o parcialmente destruido y su reconstrucción sea imposible.

En todo caso, el inciso $5^{\circ}$ del artículo 72 pareciera ampliar las causales para ordenar la compensación, pues establece que “en los casos en los cuales la restitución jurídica y material del inmueble despojado sea imposible", procederá la restitución por un predio equivalente al que haya solicitado dentro del proceso, o bien se podrá establecer la compensación económica si no es posible ni la restitución ni la compensación por equivalente.

A pesar de que la Resolución 629 de 2013 establece que previamente se debe surtir la sustracción de las reservas a efectos de iniciar los procesos de restitución, en el marco de este trabajo se logró identificar que de 675 sentencias proferidas, 8 se pronunciaron frente a solicitudes de restitución de predios que se ubican al interior de las Zonas de Reserva Forestal de Ley 2 de $1959^{9}$. En cuatro de ellas se ordenó la restitución jurídica y material del predio porque 
aun cuando los inmuebles se encontraban al interior de un área reservada, el derecho de dominio respecto del cual se pretendía el resarcimiento ya se había consolidado antes de 1974, esto es, fecha en la cual se proscribió la adjudicación de baldíos en su interior ${ }^{10}$. En todo caso el juez ordenó que el uso de los predios restituidos debería ajustarse a las finalidades de la reserva.

En las otras cuatro sentencias se ordenó la compensación con otro predio, en tanto la restitución material del predio original resultaba imposible ya que para ello debería surtirse por parte de INCODER el proceso de adjudicación del baldío abandonado. En tres de dichos procesos los representantes de las víctimas lograron demostrar la existencia de títulos de adjudicación por parte de INCODER posteriores a 1974, base sobre la cual consideraron que se debía aplicar la presunción de legalidad de dichos actos administrativos y por consiguiente solicitaron se reconociera el derecho a la restitución. No obstante, el juez desestimó tales alegatos y por ser imposible la adjudicación del predio, ordenó la compensación ${ }^{11}$.

De conformidad con lo anterior, la compensación ha sido una alternativa que han encontrado algunos jueces para dar solución al problema. En efecto, no se levanta la afectación ambiental y tampoco se desconocen los derechos de las víctimas, se logra por tanto la protección del derecho colectivo a gozar de un ambiente sano y los derechos individuales de los restituidos. No obstante, la compensación podría ser una buena alternativa para predios en los que en efecto no sea posible la intervención del hombre, como por ejemplo, aquellos que hacen parte del Sistema Nacional de Parques Nacionales Naturales que tienen un estándar de protección mucho más elevado que las Zonas de Reserva Forestal de Ley 2 de 1959, en las cuales, en efecto, se pueden realizar varios tipos de actividades económicas.

\subsection{Alternativas productivas sostenibles en zonas de reserva forestal}

Teniendo en cuenta que existe la posibilidad de restituir a las víctimas que dejaron abandonadas tierras de la Nación al interior de Zonas de Reserva Forestal de Ley 2 de 1959, resulta pertinente determinar algunas alternativas productivas sostenibles que eventualmente se podrían realizar y que serían viables en el marco de la política de restitución.

Como ya se vio existe un amplio catálogo de actividades que se pueden desarrollar al interior de las áreas reservadas sin necesidad de sustracción. Aparte de aquellas relacionadas con la reconversión de actividades agropecuarias hacia esquemas amigables con el medioambiente, vale la pena centrarse sobre aquellas que pueden ser factores de generación de ingresos para los campesinos restituidos. En ese sentido, las resoluciones que adoptan la zonificación y la ordenación de las reservas y la Resolución 1527 de 2012 del Ministerio de Ambiente y Desarrollo Sostenible son una primera base que resulta importante consultar.
Las sentencias 761113121001-2012012-0013-00 del 16 de septiembre de 2013; 761113121001201-2012001200 del 6 de septiembre de 2013; 7611131210012012-00009-00 del 24 de septiembre de $2013 y$ 761113121001-2012-012 0016-00 del 13 de septiembre de 2013 fueron sustanciadaspor el Juzgado $1^{\circ} \mathrm{Ci}$ vil del Circuito Especializadoen Restitución de Tierras de Guadalajara de Buga. Los predios se encuentran ubicados en la Zona de Reserva Forestal del Pacífico.

11 Las sentencias 200013121001-201200225-00 del 30 de mayo de 2013, y 2000131210012013-00025-00 del 8 de agosto de 2013 fueron sustanciadas por el Juzgado $1^{o}$ Civil del Circuito Especializado en Restitución de Tierras de Valledupar. Los predios se encuentran en la Zona de Reserva Forestal de la Sierra Nevada de Santa Marta. Igualmente, la sentencia 76-111-31-21-0032013-00065-002013-65 del 12 de mayo de 2014 fue sustanciada por el Juzgado $3^{\circ}$ Civil del Circuito Especializado en Restitución de Tierras de Guadalajara de Buga. El predio solicitado en restitución se encuentra en la Zona de Reserva Forestal del Pacífico.

\section{territarios 35}


${ }^{12}$ La Ley 139 de 1994 crea el Certificado de Incentivo Forestal como una herramienta que busca reconocer las externalidades positivas de la reforestación de plantaciones protectoras o productoras. Sin embargo, esta norma ha sido reglamentada entre otras por el Decreto 900 de 1997 que determina que no podrán ser objeto del incentivo áreas que sean propiedad de la Nación, lo cual nos remite nuevamente a la necesidad de titulación de dichos baldios a favor de la población beneficiaria de la restitución que ya abordamos previamente.

\section{territarias 35}

De acuerdo con dichas normas es factible, siempre que no incluya estructuras duras, implementar infraestructura para la recreación pasiva y el senderismo, pero más importante aún, desarrollar actividades que hagan parte de programas o proyectos de restauración ecológica, recuperación o rehabilitación de ecosistemas siempre que sea soportado por mandato legal o por ser un programa o proyecto de la autoridad ambiental, de los entes territoriales o propuestas particulares debidamente autorizadas.

Frente a la primera alternativa se requeriría un acompañamiento del Estado en la entrega del predio, y en cumplimiento del principio de estabilización y retorno del que trata la Ley 1448, facilitar las condiciones para que los campesinos puedan desarrollar proyectos productivos relacionados con recreación pasiva. En todo caso, las actividades que tiendan hacia la restauración, recuperación o rehabilitación de ecosistemas serán el factor que permita una verdadera armonización entre las políticas de conservación ambiental y de restitución de tierras.

Por otra parte, algunas cifras indican que para el periodo 2011-2013 la tasa de deforestación ha sido alta en Colombia al abarcar 147.946 hectáreas anuales (Centro de Prensa Internacional, 2013). De acuerdo con lo anterior, vale la pena mencionar la relevancia que cobra la implementación de estrategias de Pago por Servicios Ambientales - PSA - Estas han sido estudiadas por Wunder (2005) en torno a cinco criterios: i) son transacciones voluntarias mediante las cuales; ii) un servicio ambien- tal bien definido, o un uso de la tierra que promueva la provisión de ese servicio; iii) es comprado por al menos un comprador; iv) a al menos un proveedor; y v) sí, y solo sí, el proveedor asegura la provisión continua del servicio (condicionalidad).

Del mismo modo, Albán et al. (2008) han identificado que los servicios ambientales sobre los cuales se han implementado PSA han sido: i) la fijación de Carbono que está basado en el MDL de Kyoto, así como otros mercados que buscan prevenir la deforestación o degradación evitada; ii) la protección de cuencas; iii) belleza escénica, que versa sobre servicios de ecoturismo y el cual se realiza sobre bosques de alta calidad biológica, accesibilidad y atractivos naturales especiales; y iv) biodiversidad, que es un área emergente y cuyo principal problema ha sido la falta de compradores de este servicio. Para ello propone que se maneje un esquema de pagos insertados sobre servicios que presta el mismo ecosistema, por ejemplo, agua, carbono y turismo, entre otras.

Lo anterior es apenas una breve referencia de estrategias a nivel global, sin embargo tiene pertinencia indagar sobre las posibilidades de desarrollar este tipo de actividades sobre predios que se encuentren en Zonas de Reserva Forestal de la Ley 2 de 1959, y que por supuesto persigan sus mismas finalidades.

En su estudio de evaluación del PSA, Blanco, Wunder y Navarrete (2008) identificaron y evaluaron algunas experiencias en Colombia, destacando en ellas el Certificado de Incentivo Forestal de Conserva- 
ción ${ }^{12}$ y de Reforestación ${ }^{13}$ y el programa de familias guardabosques.

Por otra parte, en relación con las aguas, el artículo 210 de la Ley 1450 de 2011 modificó lo que la Ley 99 de 1993 regulaba en torno a la adquisición de áreas de interés para acueductos municipales y regionales. En tal virtud, dispuso que los "departamentos y municipios dedicarán un porcentaje no inferior al $1 \%$ de sus ingresos corrientes para la adquisición y mantenimiento de dichas zonas o para financiar esquemas de pago por servicios ambientales". Dicha disposición fue reglamentada por el Decreto 953 de 2013. Conforme a ello, podrían ser beneficiarios del esquema de PSA los propietarios o poseedores de predios que contengan características ecosistémicas importantes para mantener el recurso hídrico utilizado en los acueductos. Dicha norma también contempla la posibilidad de que los esquemas de PSA estén dirigidos hacia el mantenimiento de dichas zonas lo cual no necesariamente requiere de la compra o adquisición de los predios.

Ahora, los Mecanismos de Desarrollo Limpio - MDL también son otra alternativa para la sostenibilidad de los campesinos restituidos. Con fundamento en la Ley 164 de $1994^{14}$ y 629 de $2000^{15}$ se ha ido construyendo todo el andamiaje institucional a efectos de operativizar la puesta en marcha de esta estrategia. Conforme a ello se construyó el documento Conpes 3242 del 25 de agosto de 2003 por medio del cual se delineó la "estrategia institucional para la venta de servicios ambientales de mitigación del cambio climático", y el
Conpes 3700 del 14 de julio de 2011 , por medio del cual se crea la "Estrategia institucional para la articulación de políticas y acciones en materia de cambio climático en Colombia".

En la Segunda Comunicación Nacional de Colombia ante la Convención Marco de las Naciones Unidas Contra el Cambio Climático - $\mathrm{CMNUCC}^{16}$, se informó que:

Hasta diciembre de 2009, las actividades desarrolladas por el Grupo de Mitigación de Cambio Climático han permitido la consolidación de un portafolio nacional de 144 proyectos, de los cuales 49 tienen aprobación nacional por solicitud directa de los proponentes, 20 proyectos están registrados ante la CMNUCC y 6 cuentan con Certificado de Reducción de Emisiones (CER). La distribución de estos proyectos por sectores se resume así: energético $(31,25 \%)$, transporte $(8,3 \%)$, forestal $(11,8 \%)$, industrial $(31,25 \%)$ y residuos $(17,36 \%)$. El potencial anual de reducción de emisiones de GEI del total de los proyectos MDL que hacen parte del portafolio nacional es de aproximadamente 16.402.496 ton CO2 equivalente, reducciones que podrían generar potenciales ingresos al país de unos USD 152.000.000. (Ministerio de Ambiente y Desarrollo Sostenible, 2012, p. 24).

Dentro de este marco, también vale la pena mencionar los proyectos REDD $+{ }^{17}$ como una alternativa productiva para las personas que han sido beneficiarias de la restitución en Zonas de Reserva Forestal de Ley 2 de 1959.
${ }^{13}$ Actualmente este Incentivo sigue vigente, se encuentra reglamentado por el Decreto 1824 de 1994 y las tarifas aplicables para 2014 se encuentran en la Resolución 386 de 2013

14 "Por medio de la cual se aprueba la Convención Marco de las Naciones Unidas sobre el Cambio Climático", hecha en Nueva York el 9 de mayo de 1992.

${ }^{15}$ Por medio de la cual se aprueba el "Protocolo de Kyoto de la Convención Marco de las Naciones Unidas sobre el Cambio Climático", hecho en Kyoto el 11 de diciembre de 1997.

${ }^{16}$ De acuerdo con la información obtenida hasta el momento, el Gobierno Nacional se encuentra en proceso de construcción de la Tercera Comunicación Nacional ante CMNUCC.

${ }^{17} \mathrm{REDD}+$ hace referencia al uso de politicas o mecanismos que incentiven la reducción de las emisiones derivadas por la deforestación y la degradación (REDD) que incluyan, tres aspectos adicionales: i) incentivar la conservación de las reservas de carbono de los bosques; ii) aumentar dichas reservas en los paises en desarrollo, y iii) la gestión sostenible de los bosques.

territarias 35 
En Colombia se han ido implementando esfuerzos importantes para reducir la deforestación, como la Estrategia Colombiana de Desarrollo Bajo en Carbono ECDBC, y la Estrategia Nacional para la Reducción de Emisiones por Deforestación y Degradación de Bosques - ENREDD+. Bajo ese esquema, hasta el 2012 se han logrado grandes resultados de financiación que ascienden hasta los USD33.3 millones para implementar 10 actividades a nivel nacional, especialmente en el Pacífico y la Amazonía”. (Gómez et al. 2013 p. 17).

\section{Conclusiones}

Constitucionalmente es deber del Estado colombiano garantizar el derecho a gozar de un ambiente sano y el derecho a la restitución de tierras. Ambos objetivos se pretenden realizar por medio de políticas públicas especializadas. La protección del derecho a gozar de un ambiente sano se logra entre otros mecanismos, a partir de las afectaciones ambientales reguladas por la Ley 2 de 1959, que contempla unas particularidades de uso y manejo especiales. Por Otra parte, el derecho a la restitución de tierras tiene un desarrollo incipiente, que lo entiende como un mecanismo de reparación integral de las víctimas de la violencia conforme al desarrollo legislativo establecido en la Ley 1448 de 2011.

En el complejo contexto social que afronta el país ambos regímenes jurídicos se traslapan, generándose tensiones en materia de derechos que cuentan con igual jerarquía constitucional. Esta situación se agudiza frente a campesinos que han perdido tierras baldías de la Nación que se encuentran al interior de las áreas reservadas y que por disposición legal resultan ser inadjudicables.

De cualquier forma, la prohibición de adjudicación de tierras al interior de las Reservas Forestales de Ley 2 de 1959 en ocasiones termina siendo una mera formalidad, pues en lugar de proteger el recurso forestal, fomenta el acceso informal a la tenencia de la tierra, lo que implica que no haya un acompañamiento ni vigilancia estatal para que el campesino explote los recursos naturales de acuerdo con las finalidades de las reservas, y en consecuencia, se desmejoren las condiciones ecosistémicas de los bosques.

Las soluciones planteadas por el Estado frente a estas tensiones han sido contradictorias, y podrían cuestionarse por no corresponder con los presupuestos del desarrollo sostenible. Así por ejemplo, la sustracción de las reservas a través de la Resolución 629 de 2012, brinda salidas jurídicamente viables pero que van en desmedro de los intereses ambientales al dar prelación a las finalidades de la restitución de tierras. Mientras que la compensación, medida formulada por los jueces y magistrados especializados en sus providencias, garantiza la integridad de las reservas y los derechos a la restitución pero no logra armonizar las dos políticas en tanto sigue entendiendo al campesino como un actor contrario o ajeno a las finalidades de la afectación ambiental.

De cualquier forma, la sustracción pareciera ser el camino equivocado hacia una 
gestión adecuada de los recursos naturales al interior de las reservas y hacia la armonización de los derechos a gozar de un ambiente sano y el derecho a la restitución de tierras, pues aun cuando su resultado sea el levantamiento de la afectación ambiental, los condicionamientos de uso de los predios sustraídos son similares a los que se deben aplicar para las áreas reservadas. En lugar de ello, el Estado debería enfocar sus esfuerzos para que los campesinos puedan acceder efectivamente a la tierra.

De acuerdo con ello, existen posibilidades hacia la armonización que se fundamentan en que el concepto de explotación de tierras hace crisis frente a las necesidades actuales de los campesinos y del medioambiente, por lo que es necesario reinterpretarlo, lo cual es posible desde el principio de justicia transicional de la Ley 1448 de 2011 y de las finalidades de protección ambiental que se fundamentan en la Constitución Política.

De acuerdo a lo anterior, las actividades de PSA son acordes con el marco regulatorio ambiental y restitutivo, pues aparte de apuntar hacia la conservación, restauración, recuperación o rehabilitación de ecosistemas, son propicias para la generación de ingresos y por ende aportan a la estabilidad de los campesinos en sus procesos de restitución de tierras y de retorno; y además de ello, no solo satisfacen los intereses particulares de los restituidos, sino que los servicios ambientales que pueden ofrecer cobran importancia para el beneficio colectivo.

En ese sentido, es necesario que el rol del campesino cambie de cara a la realidad ambiental actual, por tal motivo, superar que la actividad productiva campesina sea un único ejercicio de labores agropecuarias, será vital para encontrar alternativas de armonización que tiendan hacia una gestión adecuada de los recursos naturales que realmente responda a los objetivos del desarrollo sostenible.

En todo caso quedan retos por superar, pues si bien normativamente hay un andamiaje y una experiencia institucional, pareciera que el Estado no tiene la capacidad para hacer un acompañamiento adecuado a las víctimas que opten por este tipo de alternativas en el marco de la restitución de tierras. La asistencia técnica para ejercer actividades en las que el campesino no tiene experiencia, el acompañamiento financiero y la generación de mercados son apenas algunos de los obstáculos por superar para lograr la sostenibilidad de la restitución de tierras y de los proyectos de PSA. Además de lo anterior, debe tenerse en cuenta la necesidad de rediseñar el esquema institucional, pues no solo se trata de una armonización desde el debate jurídico, se requiere adicionalmente, un trabajo coordinado entre las carteras de ambiente y agricultura.

\section{Referencias}

Albán, M., Moscoso D, Southgate D. y Wunder S . (2008). Memorias del Taller Diseño de Pagos por Servicios Ambientales en Ecuador y Colombia. En Vacas, Tipo Vacas, y otras Criaturas Extrañas: ¿qué existe de PSA en Colombia y Ecua- 
dor? p. 109. Termas de Papallacta: Center for International Forestry Research.

Blanco, J. T., Wunder, S., \& Navarrete, F. (2008). La experiencia colombiana en esquemas de pagos por servicios ambientales. En Ministerio de Ambiente, Vivienda y Desarrollo Territorial, et al. Reconocimiento de los servicios ambientales. Una oportunidad para la gestión de los recursos naturales en Colombia. Bogotá.

Centro de Prensa Internacional. (2013). Nueva tasa oficial de deforestación: Colombia reduce su deforestación a 147. 946 hectáreas anuales [en línea]. Bogotá, 5 de agosto de 2013. Recuperado de http://wsp.presidencia.gov. co/cepri/noticias/2013/agosto/Paginas/20130805_05.aspx [consultado en 1 de noviembre de 2014]

Congreso de la República de Colombia, Ley 57 de 1887, Código Civil colombiano. Congreso de la República de Colombia, Ley 119 de 1919 Por la cual se reforma el Código Fiscal (Ley 110 de 1912), sobre explotación de bosques nacionales.

Congreso de la República de Colombia, Ley 2 de 1959 "por la cual se dictan normas sobre economía forestal de la Nación y conservación de recursos naturales renovables.

Congreso de la República de Colombia, Ley 99 de 1993 "Por la cual se crea el Ministerio del Medio Ambiente, se reordena el Sector Público encargado de la gestión y conservación del medio ambiente y los recursos naturales renovables, se organiza el Sistema Nacional
Ambiental, SINA, y se dictan otras disposiciones".

Congreso de la República de Colombia, Ley 160 de 1994 "por la cual se crea el Sistema Nacional de Reforma Agraria y Desarrollo Rural Campesino, se establece un subsidio para la adquisición de tierras, se reforma el Instituto Colombiano de la Reforma Agraria y se dictan otras disposiciones".

Congreso de la República de Colombia, Ley 629 de 2000, "Por medio de la cual se aprueba el "Protocolo de Kyoto de la Convención Marco de las Naciones Unidas sobre el Cambio Climático", hecho en Kyoto el 11 de diciembre de 1997".

Congreso de la República de Colombia, Ley 1448 de 2011 "Por la cual se dictan medidas de atención, asistencia y reparación integral a las víctimas del conflicto armado interno y se dictan otras disposiciones".

Congreso de la República de Colombia, Ley 1450 de 2011, "Por la cual se expide el Plan Nacional de Desarrollo, 20102014".

Constitución Política de Colombia

Corte Constitucional. Sentencia C - 649 de 1997 M.P. Antonio Barrera Carbonell. Corte Constitucional. Sentencia C - 598 de 2010 M.P. Mauricio González Cuervo. Corte Constitucional. Sentencia C - 715 de 2012 M.P. Luis Ernesto Vargas Silva.

Gómez, R., Hernández, M., Gómez, R., Guerrero, R., Valencia, I., (2013). Seguimiento a la financiación de REDD+ 2009-2012. Bogotá: Forest Trends. 
Gobierno Nacional de Colombia, Decreto 2278 de 1953, "Por el cual se dictan medidas sobre cuestiones forestales".

Gobierno Nacional de Colombia, Decreto 2811 de 1974 "por el cual se dicta el Código Nacional de Recursos Naturales Renovables y de Protección al Medio Ambiente".

Gobierno Nacional de Colombia, Decreto 1824 de 1994 "Por el cual se reglamenta parcialmente la Ley 139 de 1994".

Gobierno Nacional de Colombia, Decreto 2664 de 1994 "Por el cual se reglamenta el Capítulo XII de la Ley 160 de 1994 y se dictan los procedimientos para la adjudicación de terrenos baldíos y su recuperación."

Gobierno Nacional de Colombia, Decreto 900 de 1997 "Por el cual se reglamenta el Certificado de Incentivo Forestal para Conservación".

Gobierno Nacional de Colombia, Decreto 3570 de 2011 "Por el cual se modifican los objetivos y la estructura del Ministerio de Ambiente y Desarrollo Sostenible y se integra el Sector Administrativo de Ambiente y Desarrollo Sostenible".

Gobierno Nacional de Colombia, Decreto 953 2013, "Por el cual se reglamenta el artículo 111 de la Ley 99 de 1993 modificado por el artículo 210 de la Ley 1450 de 2011 ".

Gobierno Nacional de Colombia, Documento Conpes 3242 del 25 de agosto de 2003 por medio del cual se delineó la "Estrategia institucional para la venta de servicios ambientales de mitigación del cambio climático".
Gobierno Nacional de Colombia, Documento Conpes 3700 del 14 de julio de 2011 , por medio del cual se crea la "Estrategia institucional para la articulación de políticas y acciones en materia de cambio climático en Colombia".

Juzgado $1^{\circ}$ Civil del Circuito Especializado en Restitución de Tierras de Cali. Sentencia 760013121001- 2012-0009000 del 9 de Abril de 2013.

Juzgado $1^{\circ}$ Civil del Circuito Especializado en Restitución de Tierras de Guadalajara de Buga. Sentencia 7611131210012012-00009-00 del 24 de Septiembre de 2013.

Juzgado $1^{\circ}$ Civil del Circuito Especializado en Restitución de Tierras de Guadalajara de Buga. Sentencia 7611131210012012-012 0016-00 del 13 de Septiembre de 2013.

Juzgado $1^{\circ}$ Civil del Circuito Especializado en Restitución de Tierras de Guadalajara de Buga. Sentencia 7611131210012012012-001200 del 6 de septiembre de 2013.

Juzgado $1^{\circ}$ Civil del Circuito Especializado en Restitución de Tierras de Guadalajara de Buga. Sentencia 7611131210012012-012-0013-00 del 16 de Septiembre de 2013.

Juzgado $1^{\circ}$ Civil del Circuito Especializado en Restitución de Tierras de Valledupar. Sentencia 200013121001-201200225-00 del 30 de Mayo de 2013.

Juzgado $1^{\circ}$ Civil del Circuito Especializado en Restitución de Tierras de Valledupar. Sentencia 200013121001-201300025-00 del 8 de Agosto de 2013. 
Juzgado $3^{\circ}$ Civil del Circuito Especializado en Restitución de Tierras de Guadalajara de Buga. Sentencia 76-111-31-21003-2013-00065-002013-65 del 12 de Mayo de 2014.

Machado, C. A. (2009). Ensayos para la historia de la politica de tierras en Colombia. De la Colonia a la creación del Frente Nacional. Bogotá: Universidad Nacional de Colombia.

Ministerio de Ambiente y Desarrollo Sostenible, Resolución 629 de 2012 "Por la cual se establecen los requisitos y el procedimiento para la sustracción de áreas de reserva forestal establecidas mediante la Ley 2 de 1959 para programas de reforma agraria y desarrollo rural de que trata la Ley 160 de 1994, orientados a la economía campesina, y para la restitución jurídica y material de las tierras a las víctimas, en el marco de la Ley 1448 de 2011, para las áreas que pueden ser utilizadas en explotación diferente a la forestal, según la reglamentación de su uso y funcionamiento."

Ministerio de Ambiente y Desarrollo Sostenible. Segunda Comunicación Nacional de Cambio Climático. 2010. [en línea]. Recuperado de https://www.minambiente.gov.co/index.php/component/ content/article/486-plantilla-cambioclimatico-42\#documentos [Consultado el 15 de noviembre de 2014]

Proyecto Protección de Tierras y Patrimonio de la Población Desplazada - Accion Social. Caracterización de las Reserva Forestales de Ley $2 / 59$. Consideraciones técnicas generales sobre las posibilidades de sustracción, hacia la definición de nuevas políticas públicas con fines de formalización de tierras. Bogotá: [s.n.], 2009.

Sánchez Torres, F., Fazio Vargas, A., \& López Uribe, M. P. (2007). Conflictos de tierras, derechos de propiedad y el surgimiento de la economía exportadora en el Siglo XIX en Colombia. Bogotá: Uniandes.

Wunder, S. (2005). Pagos por servicios ambientales: Principios básicos esenciales. Indonesia: Centro Internacional de Investigación Forestal. 